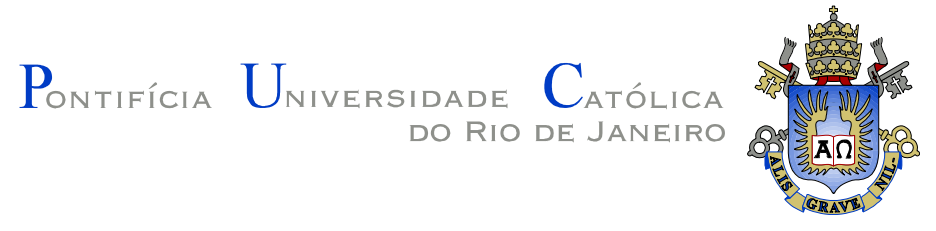

Mauro Cezar Rebello Cordeiro

\title{
Avaliação Experimental dos Efeitos de Cintilação no Canal Óptico no Espaço Livre em 780 nm, 1550 nm e 9100 nm
}

\section{Tese de Doutorado}

Tese apresentada como requisito parcial para obtenção do título de Doutor pelo Programa de PósGraduação em Engenharia Elétrica da PUC-Rio.

Orientador: Jean Pierre von der Weid 
Mauro Cezar Rebello Cordeiro

\title{
Avaliação Experimental dos Efeitos de Cintilação no Canal Óptico no Espaço Livre em 780 nm, 1550 nm e 9100 nm
}

Tese apresentada como requisito parcial para obtenção do título de Doutor pelo Programa de Pós-Graduação em Engenharia Elétrica da PUC-Rio. Aprovada pela Comissão Examinadora abaixo assinada.

\author{
Jean Pierre von der Weid \\ Orientador \\ PUC-Rio \\ Luiz Alencar Reis da Silva Mello \\ PUC-Rio \\ Rogério Passy \\ MLS \\ Maria Thereza M. Rocco Giraldi \\ IME \\ Alexandre de Oliveira Dal Forno \\ UERJ \\ Erasmus Couto Brazil de Miranda \\ UCP \\ Guilherme Penello Temporão \\ PUC-Rio \\ José Eugenio Leal
}

Coordenador(a) Setorial do Centro Técnico Científico - PUC-Rio

Rio de Janeiro, 27 de março de 2008 
Todos os direitos reservados. É proibida a reprodução total ou parcial do trabalho sem autorização da universidade, do autor e do orientador.

\section{Mauro Cezar Rebello Cordeiro}

Graduou-se em Engenharia Eletrônica, em 1994, pelo Instituto Militar de Engenharia (IME), Rio de Janeiro. No ano de 2000, obteve o título de Mestre em Engenharia Elétrica pelo IME, na área de Sistemas de Controle. Desde 2006 atua como professor do Instituto Militar de Engenharia e desenvolve pesquisa na área de Optoeletrônica e Comunicações Ópticas, com especial interesse em propagação óptica no espaço livre (FSO).

Ficha Catalográfica

Cordeiro, Mauro Cezar Rebello

Avaliação experimental dos efeitos de cintilação no canal óptico no espaço livre em 780 nm, 1550 nm e 9100 nm / Mauro Cezar Rebello Cordeiro; orientador: Jean Pierre von der Weid. - 2008.

147 f.: il. ; $30 \mathrm{~cm}$

Tese (Doutorado em Engenharia Elétrica)Pontifícia Universidade Católica do Rio de Janeiro, Rio de Janeiro, 2008.

Inclui bibliografia.

1. Engenharia elétrica - Teses. 2. Medidas no infravermelho. 3. Comunicações ópticas. 4. Propagação óptica. 5. Cintilação. 6. Turbulência. 7. FSO. I. Weid, Jean Pierre von der. II. Pontifícia Universidade Católica do Rio de Janeiro. Departamento de Engenharia Elétrica. III. Título.

CDD: 621.3 


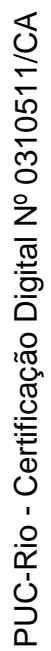

À minha esposa Luciene da Silva Demenicis. 


\section{Agradecimentos}

Ao Professor Jean Pierre von der Weid, pela orientação técnico-científica e apoio no desenvolvimento desse trabalho.

À minha esposa Luciene, pelo incentivo, apoio, compreensão e amor dedicados.

Aos meus pais, Paulo Cezar Gonçalves Cordeiro e Selene Macedo Rebello Cordeiro, pelo amor e pela sólida educação que me proporcionaram.

Ao meu irmão Maurício Cezar Rebello Cordeiro, pela amizade e companheirismo.

Ao amigo e companheiro de trabalho Claiton Pereira Colvero, que sempre esteve presente na realização e implementação dos experimentos, mesmo nas condições e horários mais adversos, pela parceria.

Ao Professor Emanoel Paiva de Oliveira Costa, pela amizade, pelos ensinamentos e pelo apoio.

Aos professores do CETUC, pela amizade e ensinamentos.

Aos funcionários do CETUC, do Departamento de Engenharia Elétrica e às secretárias Amália e Mônica, pela amizade e apoio administrativo.

Aos amigos e colegas de laboratório Djeisson, Guilherme Xavier, Janaína, Guilherme Temporão, Giancarlo, Márcia, Bessa, Thiago, Andy, Breno, Marçal, Rogério, Felipe e Daniela, pela amizade e parceria.

Ao Ministério da Defesa - Comando do Exército Brasileiro - Departamento de Ciência e Tecnologia - Instituto Militar de Engenharia pelo apoio à realização da presente Tese.

A todos aqueles que de alguma forma contribuíram para a realização desse trabalho. 


\section{Resumo}

Cordeiro, Mauro Cezar Rebello; Weid, Jean Pierre von der. Avaliação Experimental dos Efeitos de Cintilação no Canal Óptico no Espaço Livre em 780 nm, 1550 nm e 9100 nm. Rio de Janeiro, 2008. 147p. Tese de Doutorado - Departamento de Engenharia Elétrica, Pontifícia Universidade Católica do Rio de Janeiro.

A comunicação óptica por laser no espaço livre é uma área que vem despertando crescente interesse, nos últimos anos, em função da possibilidade de resolver o problema de difusão da informação, dando acesso de alta capacidade ao usuário. Sistemas ópticos sem fio oferecem rapidez na sua instalação e inicialização, além de um sistema flexível com largura de banda equivalente à da fibra óptica, em torno de 1.5 Gbps para sistemas comerciais disponíveis atualmente. O cerne da problemática que envolve as aplicações de sistemas ópticos sem fio é a propagação óptica no espaço livre. A grande diferença entre a transmissão a laser no espaço livre e na fibra óptica é a previsibilidade da atenuação da potência do sinal do laser na fibra quando comparado à atmosfera. Além da variabilidade da atenuação atmosférica devida à presença de partículas e aerossóis, um dos fenômenos que afeta a propagação de um feixe laser é a turbulência atmosférica, que ocorre mesmo em condições de alta transparência. Flutuações randômicas na temperatura do ar produzem pequenas heterogeneidades no índice de refração ao longo do caminho de propagação da luz. Essas alterações no índice de refração provocam flutuações na velocidade de fase do sinal que se propaga, causando distorção da sua frente de onda. À medida que a frente de onda se distorce e avança num meio com turbulência, ocorrem mudanças aleatórias na direção do feixe gerando flutuações na sua intensidade, contribuindo para a degradação do sinal na recepção. Nesta tese os efeitos da cintilação, decorrentes da turbulência atmosférica, foram avaliados por meio de um experimento utilizando três enlaces operando no espaço livre em três comprimentos de onda diferentes. Foi observado que o "speckle" gerado pela fibra óptica de alimentação dos transmissores de $780 \mathrm{~nm}$ and $1550 \mathrm{~nm}$ acentua os efeitos da cintilação.

\section{Palavras-chave}

Medidas no infravermelho; comunicações ópticas; propagação óptica; cintilação; turbulência; FSO. 


\section{Abstract}

Cordeiro, Mauro Cezar Rebello; Weid, Jean Pierre von der. Experimental Evaluation of Scintillation Effects in Free Space Optical Channel in 780 nm, $1550 \mathrm{~nm}$ and $9100 \mathrm{~nm}$. Rio de Janeiro, 2008. 147p. D.Sc. Thesis Departamento de Engenharia Elétrica, Pontifícia Universidade Católica do Rio de Janeiro.

Optical laser communication in free space is an area that has been attracting increasing interest in the last years, due to its possible capacity to resolve the problem of information diffusion, giving higher capacity access to users. Wireless optical systems offer speedy installation and initialization procedures and system flexibility, with the equivalent frequency bandwidth as optical fiber systems, around 1.5 Gbps for the commercial systems available nowadays. The critical aspect involving the application of wireless optical systems is free space optical propagation. The great difference between the laser free space and optical fiber transmissions is the capacity to predict the signal power attenuation that propagates into the optical fiber, when compared to the atmosphere propagation. Besides the variability of the atmospheric attenuation due to the presence of particles and aerossois, one of the phenomena that affects laser beam propagation is atmospheric turbulence, that occurs even in high transparency atmospheric conditions. Random fluctuations in air temperature generate small inhomogenities in the refraction index throughtout the light propagation path. These changes in the refraction index cause fluctuations in the phase speed of the signal that is spread over this path, causing distortion in its wave-front. As the wave-front distorts and reaches medium with turbulence, random changes occur in the beam direction, creating fluctuations in its intensity, which contribute to the degradation of the signal reception. In this thesis the effects of the scintillation, due to atmospheric turbulence, were experimentally evaluated using three free space links with three different wavelengths. The experimental results have shown that the speckle pattern generated by the optical fiber feeding the $780 \mathrm{~nm}$ and $1550 \mathrm{~nm}$ transmitters affected the link performance at these wavelengths.

\section{Keywords}

Infrared measurements; optical communications; optical propagation; scintillation; turbulence; FSO. 


\section{Sumário}

1 Introdução 20

1.1. Apresentação do Trabalho 23

2 Fundamentos dos Sistemas de Comunicações Ópticas no

Espaço Livre (FSO) 25

2.1. Espalhamento e Absorção 25

2.1.1. Espalhamento Rayleigh 28

2.1.2. Espalhamento MIE 29

2.1.3. Espalhamento Geométrico ou não seletivo 29

2.1.4. Dependência do comprimento de onda no espalhamento $\begin{array}{ll}\text { atmosférico } & 30\end{array}$

2.1.5. Cálculo do espalhamento MIE para o coeficiente de atenuação atmosférica 34

2.1.6. Espalhamento e absorção por chuva 37

2.2. Expansão do feixe por difração 38

2.2.1. Propagação do feixe gaussiano 38

2.2.2. Expansor de feixe 40

2.3. Ionização do ar 43

2.4. Desfocalização térmica 44

2.5. Detectores 45

2.5.1. Figuras de mérito dos detectores 48

2.5.2. Tipos de detectores $\quad 50$

3 Turbulência Atmosférica 55

3.1. Introdução 55

3.2. Descrição da Turbulência Atmosférica 55

3.2.1. A Constante de Estrutura da Turbulência Atmosférica $C_{v}^{2} \quad 57$

3.2.2. Os Comprimentos de Escala da Turbulência e o Subdomínio $\begin{array}{ll}\text { Inercial } & 60\end{array}$ 
3.2.3. A Constante de Estrutura do Índice de Refração do $\operatorname{Ar} C_{n}^{2} \quad 62$

3.2.4. A Densidade Espectral de Potência 63

4 Propagação de Onda Eletromagnética em Meio Aleatório 72

4.1. Introdução 72

4.2. Equação de onda em meio aleatório 73

4.3. Aproximação de Rytov $\quad 75$

4.4. A Aproximação Paraxial 82

4.5. Solução Estatística da Equação de Onda para Enlaces Laser 85

4.6. Saturação 95

4.7. Média pela Abertura do Receptor $\quad 97$

4.8. Dependência do Efeito da Cintilação com o Comprimento de $\begin{array}{ll}\text { Onda } & 100\end{array}$

4.9. Medidas Ópticas já realizadas 101

5 Desenvolvimento do Experimento 104

5.1. Introdução 104

5.2. Montagem Experimental no Sumaré 105

5.3. Montagem Experimental na PUC-Rio 109

5.3.1. Ajuste dos Transmissores 111

5.3.2. Ajuste dos Receptores 114

5.3.3. Fixação mecânica dos transmissores e receptores 117

5.3.4. Lasers, Detectores e Eletrônica 119

5.4. Avaliação da Cintilação para Máxima Abertura dos Receptores 126

5.5. Comparação Direta da Influência do "Speckle" da Fibra

$\begin{array}{ll}\text { Multimodo } & 130\end{array}$

5.6. Espectro dos sinais medidos 134

5.7. Variação da abertura dos receptores 135

$\begin{array}{ll}\text { 5.8. Diversidade Espacial } & 137\end{array}$

6 Conclusões e Perspectivas 140

7 Referências bibliográficas $\quad 142$

$\begin{array}{ll}\text { Apêndice A } & 147\end{array}$ 


\section{Lista de tabelas}

Tabela 1 - Partículas típicas responsáveis pelo espalhamento atmosférico [1].

Tabela 2 - Tipos de espalhamento onde $A_{R}, A_{M}$, e $A_{G}$ são

constantes [1].

Tabela 3 - Perdas atmosféricas (em dB/km) como função da visibilidade para $785 \mathrm{~nm}$ e 1550nm calculada a partir da eq. (2.6) [1]. Tabela 4 - Cálculos completos pela teoria de MIE para o coeficiente de atenuação em 785 nm e $1550 \mathrm{~nm}$ [1].

Tabela 5 - Perdas atmosféricas (em dB/km) como função da visibilidade calculada pela eq. (2.9).

Tabela 6 - Índice de cintilação teórico e medido tomando o enlace de 9,1 $\mu \mathrm{m}$ como referência para obtenção da constante de estrutura do índice de refração (Sumaré).

Tabela 7 - Diâmetro real e efetivo dos receptores de 780 nm e $1550 \mathrm{~nm}$ na montagem do Sumaré.

Tabela 8 - Diâmetros máximos dos transmissores e receptores dos enlaces lasers.

Tabela 9 - Índice de cintilação teórico e medido tomando o enlace de 9,1 $\mu \mathrm{m}$ como referência para obtenção da constante de estrutura do índice de refração (PUC-Rio).

Tabela 10 - Índice de cintilação teórico e medido tomando o enlace de 9,1 $\mu \mathrm{m}$ como referência para obtenção da constante de estrutura do índice de refração (PUC-Rio). 


\section{Lista de figuras}

Figura 1 - Transmitância da atmosfera em função do comprimento de onda [8].

Figura 2 - Parâmetro de tamanho das partículas espalhadoras e tipos de espalhamento [1].

Figura 3 - Eficiência de espalhamento das partículas da água

(esquerda), e distribuição do tamanho da partícula para nevoeiro denso.

Figura 4 - Reprodução dos dados de Wolff (curva sólida) e Löhle

(círculos). A curva tracejada é uma representação gráfica da eq. (2.7), sugerida por Löhle.

Figura 5 - Nova função dependência do comprimento de onda eq. (2.9). 36

Figura 6 - Perfil de intensidade do feixe Gaussiano. 38

Figura 7 - Feixe Gaussiano com cintura externa em $z=0 . \quad 39$

Figura 8 - Expansor de feixe. 41

Figura 9 - Expansor de feixe com lentes descasadas. 41

Figura 10 - Expansor de feixe com lentes propriamente casadas. 42

Figura 11 - Expansor Kepleriano. 43

Figura 12 - Expansor Galileano. $\quad 44$

Figura 13 - Ionização do ar. $\quad 44$

Figura 14 - Desfocalização térmica. $\quad 45$

Figura 15 - Emissão eletromagnética de um corpo negro [21]. 47

Figura 16 - Detectividade espectral para vários detectores

infravermelhos [21].

Figura 17 - Esquema de polarização do Fotodiodo PIN. 51

Figura 18 - Representação esquemática da geração da turbulência atmosférica. 56

Figura 19 - Representação dos comprimentos de escala da turbulência. $\quad 60$

Figura 20 - Modelos espectrais de Kolmogorov $\left(\Phi_{K}\right)$ e Tatarskii $\left(\Phi_{T}\right)$ das flutuações aleatórias do índice de refração do ar [29].

Figura 21 - Modelos espectrais das flutuações do índice de refração de Hill, Churnside e Frehlich [29]. $\quad 69$

Figura 22 - Constante de Estrutura do Índice de Refração [35]. $\quad 70$

Figura 23 - Espalhamento causado por um redemoinho que é grande 
comparado ao $\lambda$.

Figura 24 - Enlace laser com grande diâmetro e feixe colimado.

Figura 25 - Função ponderação para a variância do logaritmo das

flutuações de amplitude.

Figura 26 - Fator da Escala Interna.

Figura 27 -Geometria empregada para descrever o espalhamento de uma onda esférica.

Figura 28 - Variância da amplitude normalizada para um feixe colimado. 94

Figura 29 - O Efeito da Saturação para enlaces com diferentes distâncias.

Figura 30 - Representação esquemática da distorção da frente de onda. 96

Figura 31 - Esquemático da média por abertura para pequenas escalas de turbulência em relação ao diâmetro do receptor.

Figura 32 - Fator de ganho do receptor para onda plana e esférica.

Figura 33 - Fator de ganho do receptor medido com um laser de He-Ne em um caminho com 215,4 m.

Figura 34 - Razão da cintilação medida entre o sinal de 10,6 $\mu \mathrm{m}$ e o sinal de $632 \mathrm{~nm}$.

Figura 35 - Flutuação da intensidade do sinal normalizada e filtrada nos enlaces de 780 nm, 1550 nm, e 9,1 $\mu \mathrm{m}$ (Sumaré).

Figura 36 - Histograma das flutuações de amplitude normalizadas dos enlaces de 780 nm, 1550 nm, e 9,1 $\mu \mathrm{m}$ (Sumaré).

Figura 37 - Diagrama Esquemático da Montagem Experimental.

Figura 38 - Vista lateral dos transmissores instalados no topo do prédio Kennedy.

Figura 39 - Vista da parte traseira dos transmissores instalados no topo do prédio Kennedy.

Figura 40 - Vista lateral dos receptores instalados no prédio Leme.

Figura 41 - Dispositivo de avaliação do perfil de intensidade do feixe.

Figura 42 - Avaliação do perfil do feixe de $1550 \mathrm{~nm}$ na posição do receptor antes do ajuste de abertura.

Figura 43 - Ajuste dos transmissores.

Figura 44 - Efeito de desfocalização térmica.

Figura 45 - Diagrama do receptor com diâmetro efetivo menor do que o real. 
Figura 46 - Esquema óptico do enlace FSO aplicando-se a aproximação paraxial.

Figura 47 - Resumo dos resultados obtidos com a simulação da geometria do feixe.

Figura 48 - Canhão de 1550 nm sem a cobertura de proteção.

Figura 49 - Estrutura de fixação dos transmissores. 118

Figura 50 - Espectro da Radiação Solar [46]. 120

Figura 51 - Foto de satélite da localização do enlace na PUC-Rio 121

Figura 52 - Sinal óptico normalizado com tendência de subida. 123

Figura 53 - Receptor de 1550 nm, idêntico ao de 780 nm. 125

Figura 54 - Receptor de 9,1 $\mu \mathrm{m}$. 125

Figura 55 - Transmissores de 780 nm, 1550 nm e 9,1 $\mu \mathrm{m}$. 126

Figura 56 - Intensidade do sinal dos enlaces lasers (a), e flutuações da intensidade normalizada (b)

Figura 57 - "Speckle" decorrente dos vários modos de

$\begin{array}{ll}\text { propagação na fibra. } & 128\end{array}$

Figura 58 - Aquisição com perturbação mecânica introduzida na fibra. 129

Figura 59 - Medidas de cintilação com fibra multimodo e monomodo

em $1550 \mathrm{~nm}$ tendo como referência o enlace de 9,1 $\mu \mathrm{m}$.

Figura 60 - Intensidade do sinal dos enlaces lasers (direita), e

flutuações da intensidade normalizada (esquerda).

Figura 61 - Comparação direta da cintilação com fibra multimodo e monomodo em $1550 \mathrm{~nm}$.

Figura 62 - Espectro das flutuações de intensidade normalizadas.

Figura 63 - Desvio padrão das flutuações de intensidade,

parametrizadas pela abertura dos receptores, e pelos tipos de enlaces (1550 nm MM, 1550 nm SM, e 9,1 $\mu \mathrm{m}$ ).

Figura 64 - Flutuação da Intensidade Normalizada para os enlaces de $1550 \mathrm{~nm}$ com diversidade espacial, e 9,1 $\mu \mathrm{m}$.

Figura 65 - Desvio padrão das flutuações de intensidade normalizadas, parametrizadas pela abertura dos receptores, e pelo tipo de enlace (1550 nm com diversidade espacial e 9,1 $\mu \mathrm{m}$ ). 


\section{Lista de símbolos}

$\alpha$ - Parâmetro de tamanho ("size parameter")

$\gamma$ - Parâmetro da distribuição Gamma, constante real e positiva

$\delta$ - Função delta de Dirac tridimensional

$\varepsilon(\vec{r}, t)$ - Permissividade ou constante dielétrica do meio

$\varepsilon_{1}$ - Emissividade

$\varepsilon$ - Taxa de dissipação molecular de energia cinética da turbulência

$\zeta$ - Parâmetro de espalhamento

$\theta$ - Coordenada angular

$\theta$ - Ângulo de divergência do feixe

$\theta_{i}$ - Ângulo de divergência do feixe de entrada na lente

$\theta_{o}$ - Ângulo de divergência do feixe de saída da lente

$\Theta$ - Potencial de temperatura

$\delta \Theta$ - Potencial de temperatura elementar

$\kappa$ - Número de onda espacial da turbulência atmosférica

$\vec{\kappa}$ - Vetor número de onda espacial turbulência atmosférica

$\lambda$ - Comprimento de onda do laser

$\Lambda(\vec{\kappa})$ - Função ponderação complexa

$\mu$ - Permeabilidade magnética do meio

$v$ - Viscosidade do ar

$\rho$ - Densidade de cargas elétricas

$\sigma_{e s p}$ - Espalhamento total ou o coeficiente de atenuação total

$\sigma$ - Atenuação atmosférica ou coeficiente de extinção por unidade de comprimento

$\tau$ - Constante de tempo

$\tau(R)$ - Transmitância em um percurso de comprimento $R$

$v(\rho, R)$ - Variância do logaritmo das flutuações de amplitude normalizada

$\phi_{\max }$ - Diâmetros máximos de abertura do feixe

$\phi$ - Coordenada angular 
$\Phi_{n}(\vec{\kappa})$ - Densidade espectral tridimensional das flutuações do índice de refração

$\Phi_{n}$ - Espectro de refração

$\Phi_{\varepsilon}$ - Espectro dielétrico

$\chi$ - Logaritmo das flutuações de amplitude

$\varphi$ - Variável aleatória

$\omega$ - Freqüência temporal

$a$ - Parâmetro da distribuição Gamma, constante real e positiva

$A_{s}$ - Área da seção reta do feixe

$A_{d}$ - Área óptica do detector

A - Constante determinada pelo tamanho e distribuição das partículas

espalhadoras

$a_{r}$ - Raio do receptor

b - Parâmetro da distribuição Gamma, constante real e positiva

B - Vetor densidade de fluxo magnético

$B_{f}\left(\vec{r}_{1}, \vec{r}_{2}\right)$ - Função correlação de um campo aleatório

c - Velocidade da luz no vácuo

$C_{v}^{2}$ - Constante de estrutura da velocidade do vento

$C_{n}^{2}$ - Constante de estrutura do índice de refração do ar

$C_{\Theta}^{2}$ - Constante de estrutura do potencial de temperatura

$d$ - Diâmetro do feixe na lente

$d$ - Diâmetro do feixe na saída da lente

da - Vetor elemento unitário de área

dl - Vetor elemento unitário de comprimento

$d N$ - Amplitude randômica espectral.

$\delta n$ - Variação elementar do índice de refração

$\delta I$ - Variação elementar da irradiância

$d_{o}$ - Diâmetro do feixe no ponto de foco da lente

$D$ - Diâmetro de abertura do receptor

D - Vetor densidade de fluxo elétrico

$D^{*}$ - Detectividade

$D_{i}$ - Diâmetro do feixe de entrada sem expansão 
$D_{r r}$ - Função estrutura da componente paralela da velocidade do vento em relação ao vetor deslocamento $\vec{r}$

$D_{t t}$ - Função estrutura da componente transversal da velocidade do vento em relação ao vetor deslocamento $\vec{r}$

$D(\vec{\kappa})$ - Parte real da função ponderação

$D_{\Theta}(r)$ - Função estrutura do potencial de temperatura

$D_{i j}(\vec{r})$ - Tensor estrutura

$\Delta f_{\text {det }}$ - Largura de banda do detector

$\Delta f_{n}$ - Largura de banda da eletrônica de detecção

E - Vetor intensidade do campo elétrico

$E_{o}$ - Intensidade do campo elétrico na ausência de irregularidades

$E(\vec{\kappa})$ - Parte imaginária da função ponderação

$f$ - Comprimento focal da lente

$f_{\alpha}(t)$ - Conjunto de funções do espaço amostral

$f(t)$ - Função aleatória

$f^{*}$ - Função aleaória complexa conjugada

$f_{1}$ - Comprimento focal da lente de entrada

$f_{2}$ - Comprimento focal da lente de saída

F - Tamanho das lentes

$\# f$ - número $f$ da lente

G - Fator de ganho do receptor

$G$ - Função de Green

$h$ - Constante de Planck

H - Vetor intensidade do campo magnético

i - Número inteiro

I - Intensidade ou irradiância

$\mathrm{I}_{e s}$ - Fator da Escala Interna

$I_{C}$ - Índice de cintilação

$I_{C_{-} \text {Medido }}$ - Índice de cintilação medido

$I_{C_{-} \text {Teórico }}$ - Índice de cintilação estimado

$I_{o}$ - Intensidade média

$I_{S c}$ - Corrente de curto circuito 
$j$ - Número inteiro

$\mathbf{J}$ - Vetor densidade de corrente elétrica

$J_{1}$ - Função de Bessel de primeira ordem

$k_{b}$ - Constante de Boltzmann

$k$ - Número de onda

l - Tamanho do redemoinho

$l_{o}$ - Comprimento da escala interna dos redemoinhos

$L$ - Comprimento de escala do redemoinho espalhador

$L_{o}$ - Comprimento de escala externa dos redemoinhos

$n$ - Concentração de partículas por unidade de volume por incremento de unidade de raio

$P$ - Pressão atmosférica

$P(0)$ - Potência da fonte laser

$P(R)$ - Potência do laser a uma distância $R$

$P_{i}$ - Probabilidade de um espaço amostral

q- Constante determinada pelo tamanho e distribuição das partículas espalhadoras

$Q$ - Eficiência de espalhamento

$Q_{i}$ - Eficiência de espalhamento da i-ésima partícula

$r$ - Raio da partícula de espalhamento

$r_{i}$ - Raio da i-ésima partícula

$\vec{r}$ - Vetor deslocamento

$\vec{r}$ - Vetor posição da perturbação do meio

$R$ - Distância do enlace

$R$ - Responsividade

$\mathbf{R}$ - Vetor posição do receptor

$R(z)$ - Raio de curvatura da frente de fase

$R_{0}$ - Raio de curvatura da frente de onda

s - Distância do objeto em relação à lente

s" - Distância da imagem em relação à lente

$S$ - Espaço amostral

$T_{a}$ - Comprimento temporal da amostra

$T$ - Temperatura absoluta

$\vec{T}$ - Vetor posição do transmissor 
$v_{i}$ - Componente da velocidade

$v_{j}$ - Componente da velocidade

$v_{n}$ - Velocidade média do vento normal ao enlace

$v_{o}$ - Velocidade média do vento

$V$ - Visibilidade

$V$ - Voltagem induzida em um receptor

$V_{o c}$ - Voltagem de circuito aberto

$w$ - Raio do feixe

$w(z)$ - Raio do feixe ("spot size")

$w_{o}$ - Cintura do feixe de entrada

$w_{o}$ - Raio da cintura do feixe

$w_{o}$ - Raio efetivo da óptica de transmissão

$w_{o}$ ” - Cintura do feixe de saída

$W_{\lambda}$ - Emitância radiante espectral

$x_{i}$ - Valores discretos

$X$ - Variável aleatória discreta

Z - Distância ao longo do enlace

$z_{R}$ - Comprimento de Rayleigh do feixe de entrada

$Z_{R}$ - Domínio Rayleigh 


\section{Lista de Abreviaturas}

BER - Taxa de Erro de Bit ("Bit-Error Rate")

CW - Onda contínua ("Continuous Wave")

FOV - Campo de visão ("Field Of View")

FSO - Óptica no espaço livre ("Free Space Optics")

IP - Protocolo de internet ("Internet Protocol")

ISDN - "Integrated Services Digital Network"

LMDS - Serviço de distribuição local multiponto ("Local Multipoint Distribuition

Service")

LWIR - Infravermelho de ondas longas ("Long Wave Infrared")

LWIR - Região de comprimentos de onda na faixa do infravermelho ("Long

Wavelength Infrared")

MM - Multímodo

MWIR - Infravermelho de ondas médias ("Medium Wave Infrared")

$N E P$ - Potência equivalente de ruído ("Noise Equivalent Power")

NIR - Infravermelho próximo ("Near Infrared")

PIN - Fotodiodo tipo PIN (tipo p - intrínseco - tipo n)

QDIP - Fotodetectores de pontos quânticos ("Quantum Dot Infrared

Photodetector")

QLC - Lasers quânticos em cascata ("Quantum Lasers Cascate")

QWIP - Fotodetectores de poços quânticos ("Quantum Well Infrared

Photodetector")

RF - Rádio-frequência

SM - Monomodo

SWIR - Infravermelho de ondas curtas ("Short Wave Infrared")

TEM - Transverso Eletromagnético

UHF - "Ultra-High Frequency"

VDSL - "Very High-Speed Digital Subscriber Line" 